\title{
A Conceptual Model of Mobile Augmented Reality for Hearing Impaired Museum Visitors' Engagement
}

\author{
https://doi.org/10.3991/ijim.v14i17.16649 \\ Esraa Jaffar Baker ${ }^{(凶)}$ \\ The University of Mustansiriyah, Baghdad, Iraq \\ esraajaffar26@outlook.com \\ Juliana Aida Abu Bakar, Abdul Nasir Zulkifli \\ Universiti Utara Malaysia, Kedah, Malaysia
}

\begin{abstract}
Many studies have begun to consider how to ensure a pleasant experience during visits to cultural heritage sites and museums. Although, when considering the populace of the visitors to these sites, the hearing impaired (HI) visitors which made up of a smaller percentage, have not been in the literature limelight as much as the normal hearing visitors. Thus, the hearing impaired tends to endure certain unpalatable experiences leading to dissatisfaction of their visits. Literature has shown that Mobile Augmented Reality (MAR) can improve the experiences of visitors to the museum in terms of engagement, enjoyment and learning. This is evident in a number of articles tailored towards normal hearing visitors. However, a recent study has taken into consideration the hearing--impaired visitors by identifying the engagement elements of MAR for the $\mathrm{HI}$ museum visitors. The identified elements include; aesthetics, interaction, interest, usability, satisfaction, motivation, curiosity, enjoyment, perceived control, selfefficacy, and focused attention. This article thus takes a step further by introducing the MAR for the HI museum visitors' engagement (MARHIME) conceptual model. These elements are derived from a review of literature which has been done comprehensively and are validated by a panel of experts. Altogether eleven elements went through the expert review process and only six elements were validated to be used for the construction of the MARHIME model. This article also further grounds the justification of these selected six elements in relation to engagement. Future work will include the development of the MARHIME prototype which will be used to validate the model among the hearing-impaired visitors at a museum.
\end{abstract}

Keywords - MARHIME Conceptual Model, Hearing Impaired, Mobile Augmented Reality, Engagement, Museum.

\section{Introduction}

Augmented Reality (AR) is the superimposition of computer-generated information over the users' view of the real physical environment, which generates an augmented environment [8]. Thus, an augmented environment can be defined as an environment 
where physical objects are directly superimposed by computer-generated objects. AR is greatly impacting human interaction with computers with the propagation of MAR apps and providing support socially for various fields such as tourism, healthcare and education [62], [48], [58], [11], [12], [13] and [14]. Based on studies by [8], [21], [18], [20], [30], MAR apps have been applied in museums. The apps function as supplements to the typical paper-based information guides and brochures. MAR museum app is able to assist the museum to organize large group of visitors whenever the app is easy to use and learn and provide engaging and enjoyable experiences to them.

There are few previous studies that have explored engagement factors on education platform such as [40]. Their study revolves around user engagement and the usage of a technological platform for education. Their study indicated that engagement comprises of four distinguishable phases namely point of engagement, a period of sustained engagement, disengagement, and re-engagement. In fact, they identified nine attributes of user experience that influence users' engagement on technology usage that include; challenge, endurability, positive effect, aesthetic and sensory appeal, perceived user control, attention, feedback, interactivity, and variety/novelty. However, their study mainly focused on normal hearing users and not HI users. Likewise, the technology referred in their study is not MAR which is why elements of MAR were not included. Besides, they did not consider museum environment, which is the major consideration of this study. As mentioned previously, the study of [40] never considered engagement and mobile AR factors however, these two were considered in a study by [47]. In the study, they identified eight factors that maximize the impact of users' engagement for MAR game development that include; Clear Goals, Satisfaction, Focused Attention, Mixed Fantasy, Perceived Usability, Challenge, Interaction and Social. Their study focused on engagement and MAR and their target was normal hearing users and not HI users. In addition, their study did not explore issues on museum learning platform whereas the present study mainly focuses on the HI visitors' engagement within the museum site. According to [26], several researchers are focusing on museum MAR apps that target visitors with normal hearing and less focus on the HI visitors. Thus, the present study is unique as it identifies the gaps of previous studies and starts to address the gaps.

Studies by [3] and [4] investigated the elements of MAR for the HI museum visitors' engagement. It introduces eleven elements that are required in designing an MAR app for HI visitors' engagement at the museum based on the literatures from previous studies related to MAR and engagement. The elements comprise of Aesthetics [22], Curiosity [9], Usability [41] and [26, Interaction [27], Motivation [25], Satisfaction [1], Self-Efficacy [6] and [32], Perceived Control [9], Enjoyment [46] and [67], Focused Attention [40] and Interest [55]. This study selects and validates only the relevant and appropriate elements before proceeding to the next phase, which involves the construction of the MARHIME conceptual model.

This paper is arranged as follows; Section II addresses the literature review, Section III introduces the elements of MAR engagement for HI while Section IV elaborates on the methodology for content validity (expert validation) of the elements. The findings from the validation are highlighted in Section $\mathrm{V}$ followed by discussion on the relation 
of the resulting elements with engagement in Section VI. Section VII concludes this article.

\section{Review of Literature}

AR is an expanding field and it is part of Mixed Reality. [38] explained many misunderstandings in terms of classification and definition of AR. In their study, classification and definition of AR were based on a Reality-Virtuality Continuum as depicted in Figure 1. Based on Figure 1, on the left side of the continuum is the real environment where humans interact with actual and physical quantities while on the right side is the virtual environment, which is the computer-generated environment. The main difference between the real and virtual environments is that virtual environment consists of synthetic environment while real environment comprises of non-synthetic environment. Besides the two environments, there are two other different environments namely; Augmented Reality and Augmented Virtuality (AV). AV incorporates real life into the virtual environment [61] and [51]. Meanwhile, for AR, the virtual objects are incorporated into the real environment [24] and [50]. Based on this continuum, AR is gaining attention in recent years due to its nature [5].

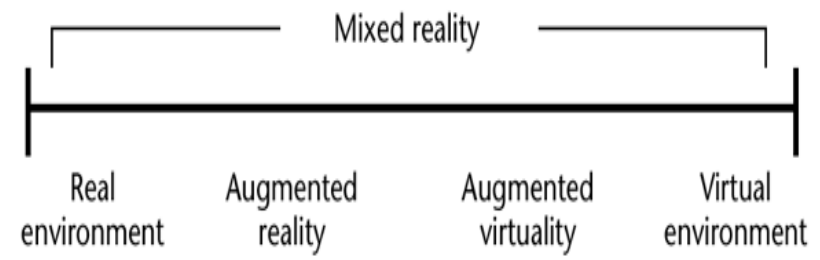

Fig. 1. Reality-Virtuality Continuum [38]

MAR is a type of AR, which enables uninterrupted users' interaction with the augmented environment. It enables users to move and freely interacting with the augmented environment while in focus in achieving the targeted goal. The same situation is aimed for the MAR app for the museum. Some studies in the museum MAR domains include models such as enjoyable informal learning MAR [45] which focuses on enjoyment and learning during the museum visits, mobile augmented reality tour (MART) [66] which contributes to context-awareness and artefacts' information in the museum, and Tech Cool Tour [63], an Augmented 3D reconstruction, 3D virtual character, video, and 360 degrees panorama of the heritage site. Other models include data flow and framework of AR-based on-site tour guide [57], Architecture of Sutoon-Hoo MAR [2], and MobiAR, a mobile service platform for tourist information based on MAR [37].

Most of these aforementioned models focus on formal and informal learning however, little attention is given to users' engagement [17]. Majority of the studies within the vast literature focus more on other engagement mobile apps for normal hearing people while less attention is given to engagement of mobile app for HI people. Likewise, the most used class is the mobile guide app because it provides detail information 
and learning platform to users. Table 1 summarizes some studies that explore MAR apps for the HI people. Based on that table, MAR has been used for HI communication, teaching and learning purposes. For instance, studies by [39] and [16] show that MAR enhances speech narration and conversion into readable text which makes communication easier for the HI community. Similarly, studies by [44], [34] and [42] reflect the importance of MAR in learning for the HI people. These studies suggest that MAR can provide a unique platform for $\mathrm{HI}$ interaction and stimulating learning environment.

Table 1. MAR apps for the HI

\begin{tabular}{|c|c|c|c|c|c|c|}
\hline Researcher & Description & Remarks & Features & Variables & \begin{tabular}{|c|}
$\begin{array}{c}\text { Target Audi- } \\
\text { ence }\end{array}$ \\
\end{tabular} & Domain \\
\hline [39] & $\begin{array}{l}\text { A communica- } \\
\text { tion system for } \\
\text { the deaf, disa- } \\
\text { bled and ordi- } \\
\text { nary people to } \\
\text { communicate } \\
\text { with each } \\
\text { other. }\end{array}$ & $\begin{array}{l}\text { ASRAR deliv- } \\
\text { ers the speech, } \\
\text { converts it into } \\
\text { readable text, } \\
\text { and displays } \\
\text { the text di- } \\
\text { rectly on the } \\
\text { AR display. }\end{array}$ & $\begin{array}{l}\text { Automatic } \\
\text { Speech } \\
\text { Recognition } \\
\text { (ASR) and } \\
\text { Text-to- } \\
\text { Speech Syn- } \\
\text { thesis (TTS) }\end{array}$ & $\begin{array}{l}\text { Interest and } \\
\text { Interaction }\end{array}$ & $\begin{array}{l}\text { Deaf and Dis- } \\
\text { abled }\end{array}$ & $\begin{array}{l}\text { Communica- } \\
\text { tion }\end{array}$ \\
\hline [16] & \begin{tabular}{|l} 
iHeAR is an \\
interactive \\
system for HI \\
and deaf.
\end{tabular} & $\begin{array}{l}\text { Use iPhone } \\
\text { and iPad } 2 \text { as } \\
\text { the interaction } \\
\text { and platform } \\
\text { devices. }\end{array}$ & $\begin{array}{l}\text { Speech recog- } \\
\text { nition, and } \\
\text { language mod- } \\
\text { eling }\end{array}$ & $\begin{array}{l}\text { Interaction } \\
\text { and social ac- } \\
\text { ceptance (net- } \\
\text { working) }\end{array}$ & $\begin{array}{l}\text { HI and } \\
\text { deaf }\end{array}$ & $\begin{array}{l}\text { Communica- } \\
\text { tion }\end{array}$ \\
\hline [42] & $\begin{array}{l}\text { Auras: Aug- } \\
\text { mented Real- } \\
\text { ity educational } \\
\text { application. }\end{array}$ & $\begin{array}{l}\text { Mobile Aug- } \\
\text { mented Real- } \\
\text { ity (MAR) ap- } \\
\text { plication to fa- } \\
\text { cilitate Quick } \\
\text { Response } \\
\text { (QR) Codes in } \\
\text { deaf children } \\
\end{array}$ & $\begin{array}{l}\text { Quick Re- } \\
\text { sponse (QR) } \\
\text { Codes, sign } \\
\text { language, and } \\
\text { 3D. }\end{array}$ & $\begin{array}{l}\text { Engage, reten- } \\
\text { tion and learn }\end{array}$ & Deaf & $\begin{array}{l}\text { Teaching and } \\
\text { Learning }\end{array}$ \\
\hline [44] & $\begin{array}{l}\text { Learning op- } \\
\text { portunities for } \\
\text { deaf students. }\end{array}$ & $\begin{array}{l}\text { Purpose of en- } \\
\text { hancement of } \\
\text { an on-site field } \\
\text { trip experi- } \\
\text { ence. }\end{array}$ & $\begin{array}{l}\text { 2D barcode } \\
\text { image and } \\
\text { American } \\
\text { Sign Lan- } \\
\text { guage (ASL). }\end{array}$ & $\begin{array}{l}\text { Enjoyment } \\
\text { and satisfac- } \\
\text { tion }\end{array}$ & Deaf & Learning \\
\hline [34] & $\begin{array}{l}\text { Learning for } \\
\text { HI students. }\end{array}$ & $\begin{array}{l}\text { In-class hear- } \\
\text { ing in assist- } \\
\text { ing HI and } \\
\text { deaf students }\end{array}$ & $\begin{array}{l}\text { Mixed reality } \\
\text { and non-ver- } \\
\text { bal communi- } \\
\text { cation. }\end{array}$ & $\begin{array}{l}\text { Engagement } \\
\text { and Interest }\end{array}$ & $\mathrm{HI}$ and Deaf & Learning \\
\hline [43] & $\begin{array}{l}\text { A Google } \\
\text { glass app for } \\
\text { the deaf stu- } \\
\text { dents to en- } \\
\text { gage them in a } \\
\text { classroom. }\end{array}$ & $\begin{array}{l}\text { A Google } \\
\text { glass app that } \\
\text { enables the } \\
\text { deaf students } \\
\text { to look at the } \\
\text { QR code of an } \\
\text { object in the } \\
\text { classroom. }\end{array}$ & $\begin{array}{l}\text { Scan a QR } \\
\text { code for an } \\
\text { object and } \\
\text { watch video. }\end{array}$ & Engagement & Deaf & Learning \\
\hline
\end{tabular}

Nevertheless, it is observed that there are limited studies on MAR in engaging the HI tourists. The issue of users' engagement is a very important concept in museum 
visitation because engagement enhances users' entertainment, learning, and acceptability, which have a direct influence on tourists' experiences [28]. Therefore, this present study will focus on the conceptual model of MAR for the HI visitors' engagement at the museum site. In view of this, the next section will examine the needs and issues that surround the HI people whereas specific reviews will be made on the nature and classification of HI, which will be used to guide this present study.

\section{Elements of Mar for Engagement of $\mathrm{HI}$}

Mobile engagement defines the range of interaction among the MAR app and the user. This interaction is very important because it depicts the level of engagement. According to [36], the more persuasive the interaction, the more engaging the MAR application is. Hence, it is imperative to consider the elements that will enhance persuasive interaction and engagement between the MAR application and its users. [54] mention that mobile interaction takes place in four circumstances namely; the mobile app, the app content, third parties and assignment. The mobile app refers to the movable personalized electronic device while the app content means the information on the mobile app. Third parties means the ability for the user to relate to the contents in the app as a different entity while the assignment means the tasks that are needed to be completed in order to stay connected with the third parties in the mobile app.

The utilization of these four circumstances produces an emotional commitment and involvement interaction between the app and the user. This emotional commitment and involvement interaction define the engagement of the MAR app. However, the rationale to comprehend this engagement is a major issue with many MAR apps especially for the HI people.

\section{$4 \quad$ Methodology}

In determining the most suitable elements to be used in the construction of the MARHIME conceptual model, three steps were followed. The steps include; systematic literature review, focus group, and expert review. The details of the first step are discussed in detail by [4] and 20 MAR elements have been identified. Focus group being the second step is a series of carefully planned discussions designed to gain insights into the fields defined in the permissive and uncertain environment [33]. Focus group involved eleven participants including five HI students, three HI teachers, two counselors and one museum staff and the participants' profile is shown in Table 2. 
Table 2. Profile of the Focus Group Participants

\begin{tabular}{|c|l|l|l|l|c|}
\hline Participant & Age & \multicolumn{1}{|c|}{ Gender } & $\begin{array}{c}\text { Level of Educa- } \\
\text { tion }\end{array}$ & Field of work & $\begin{array}{c}\text { Experience } \\
\text { (year) }\end{array}$ \\
\hline 1 & 19 & Male & Secondary school Student & - \\
\hline 2 & 18 & Male & Secondary school Student & - \\
\hline 3 & 17 & Male & Primary school & Student & - \\
\hline 4 & 16 & Female & Primary school & Student & - \\
\hline 5 & 21 & Male & Secondary school Student & - \\
\hline 6 & 30 & Male & Primary school & Museum Staff & 5 \\
\hline 7 & 33 & Female & Degree & Counselor & 8 \\
\hline 8 & 35 & Male & Degree & Counselor & 12 \\
\hline 9 & 37 & Female & Degree & Teacher & 10 \\
\hline 10 & 45 & Female & Degree & Teacher & 17 \\
\hline 11 & 51 & Male & Degree & Teacher & 23 \\
\hline
\end{tabular}

The focus group session began with a brief presentation by the researcher with the help of a HI teacher. All the participants were explained about the 20 elements by providing detail descriptions of each element. They were allowed to ask any questions related to the elements. Then the participants were asked to fill out a form that has been prepared for the purpose of selecting the most appropriate MAR engagement elements.

Table 3 and Figure 2 show the results of the focus group. Based on the results, the eleven selected elements have frequencies of ten or eleven "yes" responses and they are; Aesthetics, Usability, Motivation, Focused Attention, Perceived Control, Curiosity, Enjoyment, Self-efficacy, Interest, Satisfaction, and Interaction.

Table 3. Results of Focus Group

\begin{tabular}{|c|c|c|c|}
\hline No. & Elements & Yes & No \\
\hline 1 & Aesthetics & 11 & 0 \\
\hline 2 & Novelty & 2 & 9 \\
\hline 3 & Usability & 10 & 1 \\
\hline 4 & Feedback & 2 & 9 \\
\hline 5 & Motivation & 11 & 0 \\
\hline 6 & Focused Attention & 10 & 1 \\
\hline 7 & Perceived Control & 10 & 1 \\
\hline 8 & Curiosity & 10 & 1 \\
\hline 9 & Enjoyment & 11 & 0 \\
\hline 10 & Social skill & 1 & 10 \\
\hline 11 & Self-efficacy & 10 & 1 \\
\hline 12 & Felt Involvement & 2 & 9 \\
\hline 13 & Endurability & 3 & 8 \\
\hline 14 & Interest & 10 & 1 \\
\hline 15 & Immersion & 0 & 11 \\
\hline 16 & Challenge & 1 & 10 \\
\hline 17 & Satisfaction & 11 & 0 \\
\hline 18 & Concentration & 0 & 11 \\
\hline 19 & Trust & 2 & 9 \\
\hline 20 & Interaction & 10 & 1 \\
\hline
\end{tabular}




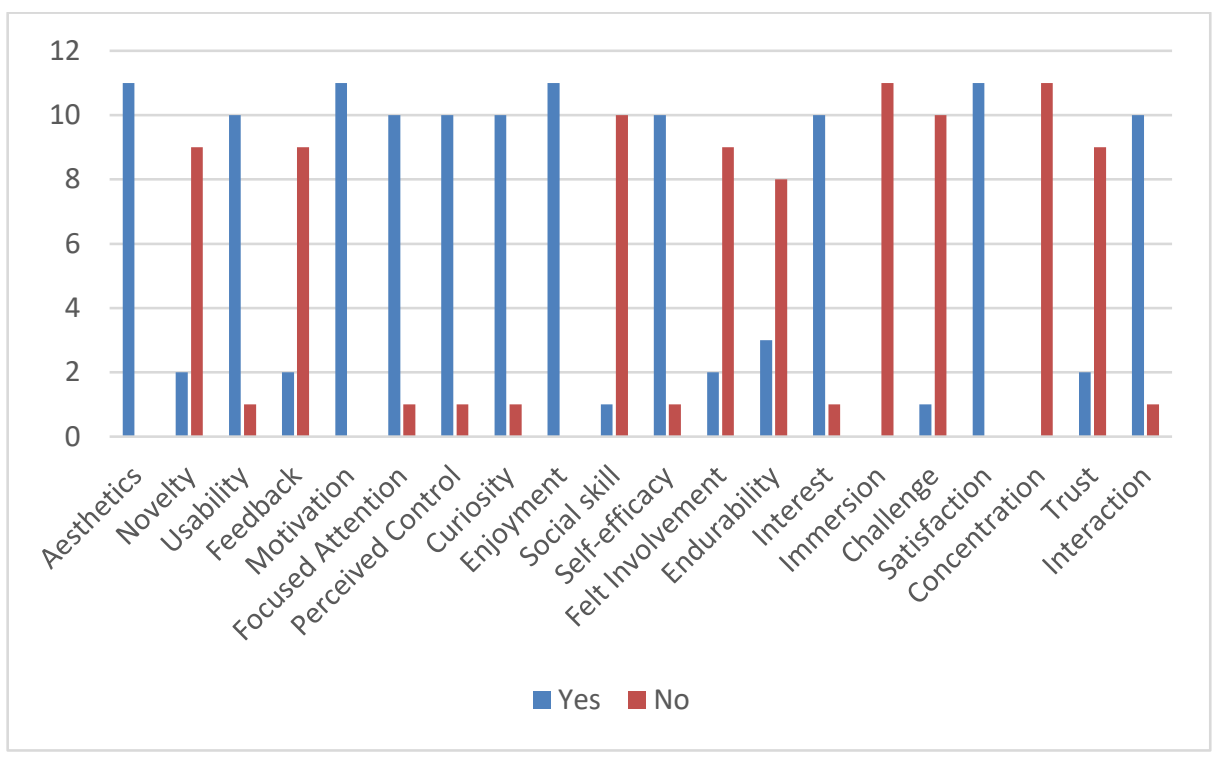

Fig. 2. Results of Focus Group

The third step involved two phases; expert review 1 and expert review 2. Eleven academic experts from the fields of AR, MAR, HI, Museum and Human Computer Interaction (HCI) from countries Malaysia, Australia, United States of America (USA) and Romania were involved. All the experts have more than five years of working experience and have $\mathrm{PhD}$ in their respective domain areas. Table 4 shows a brief summary of the experts involved in this step.

Table 4. Brief Summary of Experts

\begin{tabular}{|c|l|l|c|l|}
\hline Expert & Country & \multicolumn{1}{|c|}{ Field of Expertise } & Experience (year) & \multicolumn{1}{|c|}{ Involvement stage(s) } \\
\hline 1 & Malaysia & Museum, HCI & 18 & Expert review 1 \\
\hline 2 & Malaysia & Museum, HCI & 20 & Expert review 1 \\
\hline 3 & USA & MAR, HI & 11 & Expert review 1 \\
\hline 4 & Romania & Museum, MAR & 6 & Expert review 1 \\
\hline 5 & Malaysia & MAR, AR & 16 & $\begin{array}{l}\text { Expert review 1, } \\
\text { Expert review 2 }\end{array}$ \\
\hline 6 & Malaysia & HI, HCI, Multimedia & 14 & Expert review 1 \\
\hline 7 & Australia & HCI & 17 & Expert review 1 \\
\hline 8 & Malaysia & HCI, Multimedia & $>5$ & Expert review 1, \\
& & & & Expert review 2 \\
\hline 9 & Malaysia & Multimedia, HCI & 15 & Expert review 2 \\
\hline 10 & Malaysia & Multimedia & 15 & Expert review 2 \\
\hline 11 & Malaysia & Museum & $>5$ & \\
\hline
\end{tabular}

[35], [59] and [65] have recommended three to ten experts for content validation (expert validation). In expert review 1, eight experts were involved. The experts were asked to fill out a form that has been prepared for the purpose of selecting the most 
appropriate MAR engagement elements among the eleven elements. A three-point scale was used to measure the level of relevance of the elements. The scale comprised of; Relevant (R), maybe not relevant (M), and Definitely not relevant (D). Since the experts were from different countries, the review forms were distributed through email and also hand-delivered. The forms were all collected back using the same method in which they were distributed.

Expert review 2 involved altogether five experts. Two of the experts had already involved in expert review 1 and another three new academic experts were added to the team. A new review form was used in the expert review 2 and it consists of the elements that have been selected through expert review 1 . The new forms were handed or emailed to all the experts. All the experts provided their responses and some of them provided recommendations in written format for expert review 2.

\section{$5 \quad$ Findings}

Table 5 and Figure 3 show the results of the focus group. Based on the results, the eleven selected elements have frequencies of ten or eleven "yes" responses and they are; Aesthetics, Usability, Motivation, Focused Attention, Perceived Control, Curiosity, Enjoyment, Self-efficacy, Interest, Satisfaction, and Interaction.

Table 5. Results of Focus Group

\begin{tabular}{|c|c|c|c|}
\hline No. & Elements & Yes & No \\
\hline 1 & Aesthetics & 11 & 0 \\
\hline 2 & Novelty & 2 & 9 \\
\hline 3 & Usability & 10 & 1 \\
\hline 4 & Feedback & 2 & 9 \\
\hline 5 & Motivation & 11 & 0 \\
\hline 6 & Focused Attention & 10 & 1 \\
\hline 7 & Perceived Control & 10 & 1 \\
\hline 8 & Curiosity & 10 & 1 \\
\hline 9 & Enjoyment & 11 & 0 \\
\hline 10 & Social skill & 1 & 10 \\
\hline 11 & Self-efficacy & 10 & 1 \\
\hline 12 & Felt Involvement & 2 & 9 \\
\hline 13 & Endurability & 3 & 8 \\
\hline 14 & Interest & 10 & 1 \\
\hline 15 & Immersion & 0 & 11 \\
\hline 16 & Challenge & 1 & 10 \\
\hline 17 & Satisfaction & 11 & 0 \\
\hline 18 & Concentration & 0 & 11 \\
\hline 19 & Trust & 2 & 9 \\
\hline 20 & Interaction & 10 & 1 \\
\hline
\end{tabular}




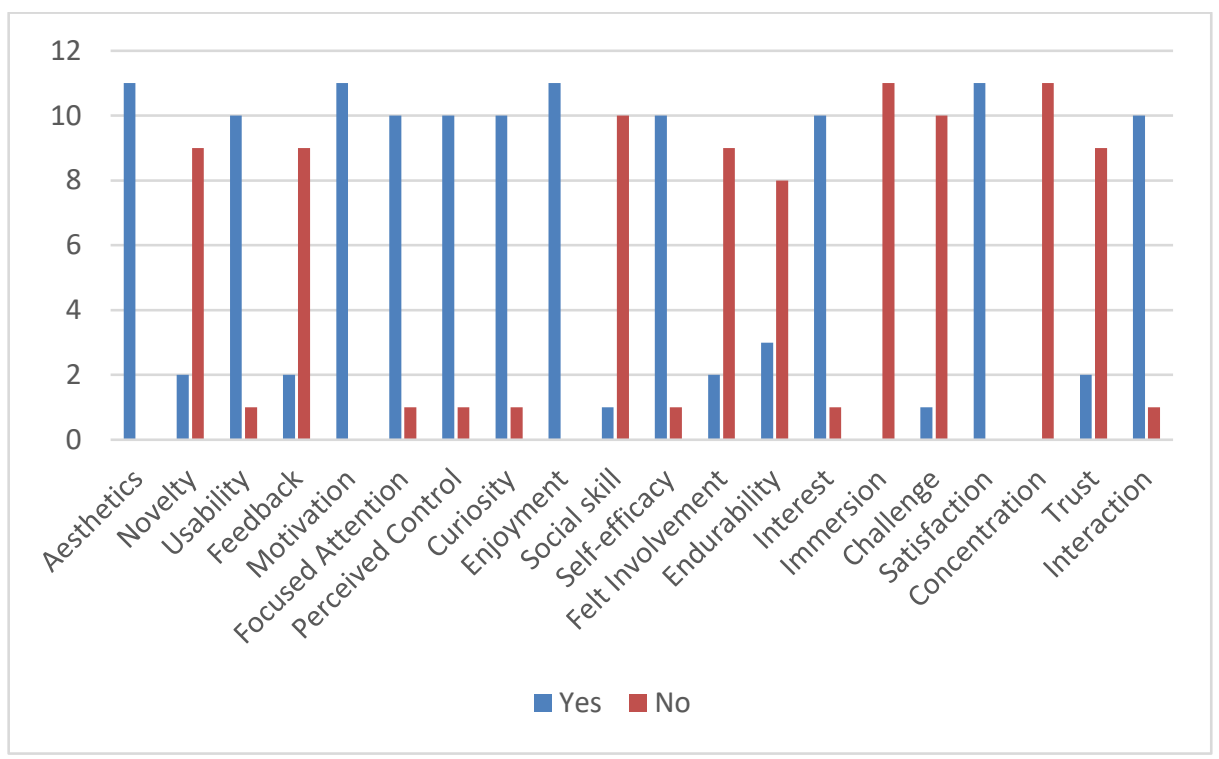

Fig. 3. Results of Focus Group

Table 6 and Figure 4 show the results of the expert review 1. As aforementioned, the requirement in selecting a suitable element for this study is based on all the experts in review 1 agreeing that the element is relevant. The results show that there are six elements in which all experts agreed that they are relevant and they are; Aesthetics, Enjoyment, Interaction, Motivation, Satisfaction and Usability. However, based on feedbacks from the experts, the proposed items for all the relevant elements required refinement and the refinements were made based in expert review 2.

Table 6. Results of Expert Review 1

\begin{tabular}{|l|c|c|c|}
\hline \multicolumn{1}{|c|}{ Element } & Relevant(R) & Maybe not Relevant(M) & Definitely not Relevant(D) \\
\hline Aesthetics & 8 & 0 & 0 \\
\hline Curiosity & 7 & 1 & 0 \\
\hline Usability & 8 & 0 & 0 \\
\hline Interaction & 8 & 0 & 0 \\
\hline Motivation & 8 & 0 & 0 \\
\hline Satisfaction & 8 & 0 & 0 \\
\hline Self-Efficacy & 3 & 5 & 0 \\
\hline Perceived Control & 7 & 1 & 0 \\
\hline Enjoyment & 8 & 0 & 0 \\
\hline Focused Attention & 6 & 1 & 1 \\
\hline Interest & 7 & 1 & 0 \\
\hline
\end{tabular}




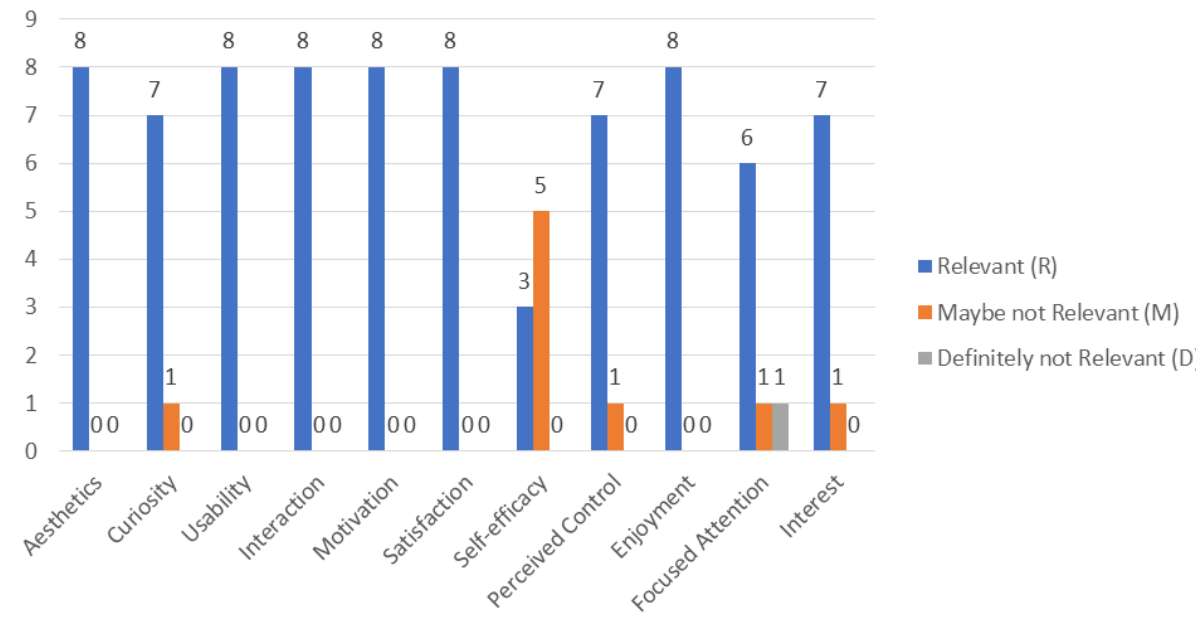

Fig. 4. Results of Expert Review 1

After the refinements were made to the items for all the six elements, the expert review 2 forms were sent to five experts together with the conceptual model. Table 7 shows the experts' responses for expert review 2. Based on Table 7, the six elements for MAR for engaging HI museum visitors have 19 items, whereby Aesthetics has three items, Usability has three items, Interaction has three items, Motivation has three items, Satisfaction has three and Enjoyment has four items.

Table 7. Experts' Responses in Expert Review 2

\begin{tabular}{|c|c|c|c|c|}
\hline Element & Items & Relevant (R) & Maybe not Relevant (M) & Definitely not Relevant (D) \\
\hline \multirow{3}{*}{ Aesthetics } & AES 1 & 5 & 0 & 0 \\
\hline & $A E S 2$ & 5 & 0 & 0 \\
\hline & AES 3 & 5 & 0 & 0 \\
\hline \multirow{3}{*}{ Usability } & USA 1 & 5 & 0 & 0 \\
\hline & USA 2 & 4 & 1 & 0 \\
\hline & USA 3 & 5 & 0 & 0 \\
\hline \multirow{3}{*}{ Interaction } & INT 1 & 5 & 0 & 0 \\
\hline & \begin{tabular}{|l|}
$I N T 2$ \\
\end{tabular} & 5 & 0 & 0 \\
\hline & INT 3 & 4 & 1 & 0 \\
\hline \multirow{3}{*}{ Motivation } & MOT 1 & 4 & 1 & 0 \\
\hline & MOT 2 & 5 & 0 & 0 \\
\hline & MOT 3 & 5 & 0 & 0 \\
\hline \multirow{3}{*}{ Satisfaction } & SAT 1 & 5 & 0 & 0 \\
\hline & $S A T 2$ & 4 & 1 & 0 \\
\hline & SAT 3 & 5 & 0 & 0 \\
\hline \multirow{4}{*}{ Enjoyment } & ENJ 1 & 5 & 0 & 0 \\
\hline & ENJ 2 & 5 & 0 & 0 \\
\hline & ENJ 3 & 5 & 0 & 0 \\
\hline & ENJ 4 & 4 & 1 & 0 \\
\hline
\end{tabular}




\section{The MARHIME Conceptual Model}

Based on expert reviews findings, it has been suggested that the conceptual model consists of two layers. The first layer represents the six MAR elements namely; Aesthetics, Usability, Interaction, Motivation, Satisfaction and Enjoyment in relation to Engagement. The combination of these six elements of Engagement representing the first layer of the conceptual model of mobile augmented reality for HI museum visitors' engagement (MARHIME) is shown in Figure 5. This conceptual model was verified by five experts who were involved in expert review 2 for all the elements and their respective items. The aim of conducting the expert review is to validate the conceptual model. In expert review 2, besides reviewing the elements, recommendations pertaining to the model were provided. The response from the experts was that they accepted the conceptual model as suitable.

The second layer is more on the technology and architecture of MARHIME consisting of four main components namely; MAR, Museum, Engagement and HI. In this layer the technology is divided into two components. The first component is the hardware that is needed for developing the MAR consisting of mobile devices. The second component is the software which includes; Vuforia, Unity3D, C++, Android SDK/Java SDK, Target Database, Target Tracking for AR marker and Multimedia Objects. The multimedia objects in this model consist of four elements; 3D model, text, video and images. The following subsection discusses each of the elements in the MARHIME conceptual model.

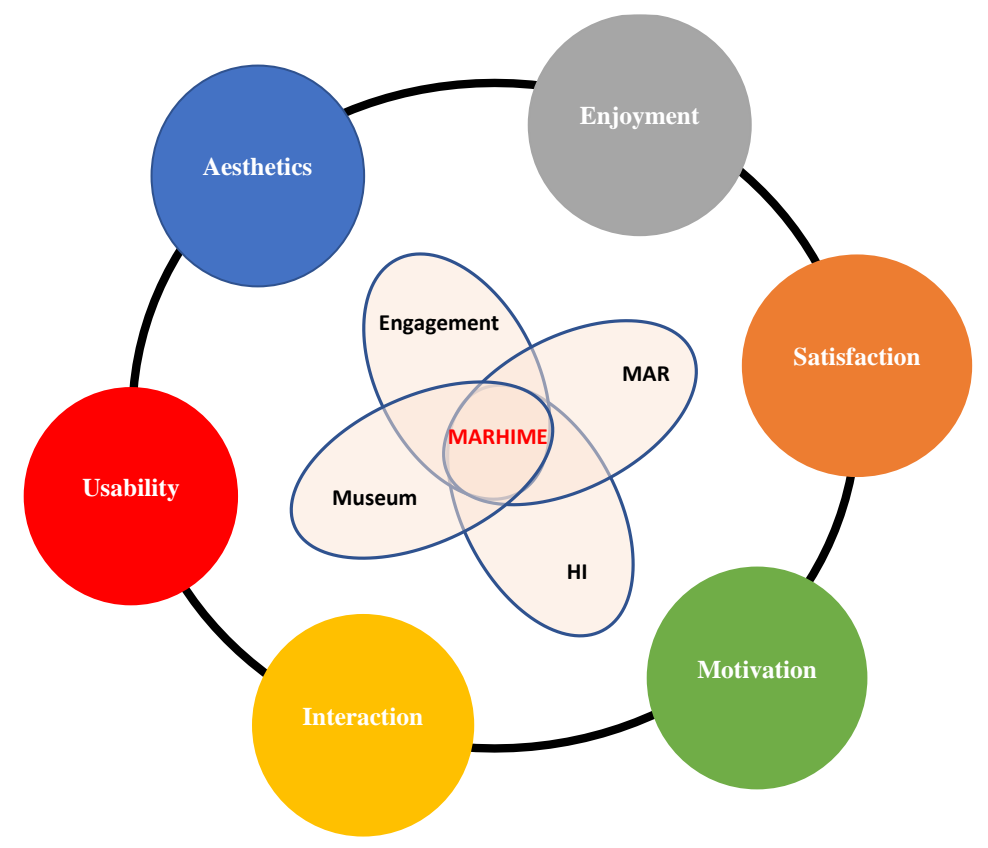

Fig. 5. The MARHIME Conceptual Model 


\section{Discussion}

This study has shortlisted six elements of MAR that form the MARHIME conceptual model. This section discusses the relation of each element with engagement as depicted in Figure 5. The discussion reflects the relationship between the elements as expressed by the MARHIME conceptual Model.

\section{a) Satisfaction}

It describes satisfaction as fun moments with the app when the users met their expectations with the app. This finding corroborates the arguments by [31] and [19] where the element of satisfaction is found to be related to users' engagement.

\section{b) Enjoyment}

It is the feeling of reaping benefits from the message conveyed by the app. Enjoyment is linked with engagement in such a way that when users are experiencing enjoyment and fun as a result of their interaction with the app, then the users' engagement with the app will be increased. This result outcome supports the findings from [29] and [64] where it can be seen that when users experience enjoyment due to their interaction with an app then it will increase the users' engagement with the app.

\section{c) Aesthetics}

It is a blend of art, beauty, and taste with MAR. In order to ensure that the users appreciate the message conveyed by the MAR app, theory of beauty is introduced. This element revolves around sight attraction and physical fascination which will compel users to continue to engage with the app. This finding is in line with [15] explanation on the linkage between aesthetics and engagement whereas the result outcomes from [60] and [10] support the fact that the element of aesthetics increases users' engagement in app interaction.

\section{d) Motivation}

It is the ability for users to accompany task. This element shows that the app should encourage users' participation in the app activities. It should fascinate users in accompanying their desired task and activities during their interaction with the app. This argument supports the conclusions from [49] and [7] studies where they pinpointed that a motivated app will increase users' engagement during user-app interaction.

\section{e) Usability}

This element consists of ease of use, learnability and flexibility of MAR. Ease of use is a measure for appraising MAR app [52]. It entails app's friendliness and content comprehension which represents the ease of use of engagement features within the app. Likewise, usability element promotes positive users' experience during users' interaction with the app. This conclusion supports arguments from [23], [56] and [53] studies 
that usability enhances the continuity usage of an app by the users and promote users' engagement.

\section{f) Interaction}

It describes how the users and app are connected. It is important since interactive platform and app communication nature will promote users' engagement. This element that link-up the users' interest and competence are deeply rooted in the users' feelings and sense-making on the mobile app. This is found to be in line with the outcomes from [60], which pointed out that interactive platform, enhances users' engagement.

\section{Conclusion}

This study has finally selected six elements of MAR for the construction of the MAR for HI Museum Visitors' Engagement (MARHIME) conceptual model. These elements comprise of; Aesthetics, Enjoyment, Interaction, Motivation, Satisfaction, and Usability. These six elements and the all the items respectively consolidated the MARHIME conceptual model. This model can be used as a guide for MAR app designers in developing a MAR app for the hearing-impaired museum visits engagement. Thus, in the near future, this research will proceed in designing and developing the MARHIME app by incorporating all the selected engagement elements.

\section{Acknowledgement}

This research was supported by the Fundamental Research Grant Scheme (SO Code 14354) received from the Ministry of Higher Education Malaysia through the School of Creative Industry Management and Performing Arts, Universiti Utara Malaysia. Special thanks to the School of Creative Industry Management and Performing Arts, Universiti Utara Malaysia for the resources and support.

\section{References}

[1] M. Alqahtani and H. Mohammad, Mobile applications' impact on student performance and satisfaction. Turkish Online Journal of Educational Technology-TOJET, 14(4), 102-112, 2015.

[2] Angelopoulou, D. Economou, V. Bouki, A. Psarrou, L. Jin, C. Pritchard and F. Kolyda, Mobile augmented reality for cultural heritage. In International Conference on Mobile Wireless Middleware, Operating Systems, and Applications (pp. 15-22). Springer, Berlin, Heidelberg, 2011. https://doi.org/10.1007/978-3-642-30607-5_2

[3] E. J. Baker, J. A. Abu Bakar and A. N. Zulkifli, Mobile augmented reality elements for museum hearing-impaired visitors' engagement. Journal of Telecommunication, Electronic and Computer Engineering (JTEC), 9 (2-12), 171-178, 2017. https://doi.org/10. $\underline{1063 / 1.5005366}$ 
[4] E. J. Baker, J. A. Abu Bakar and A. N. Zulkifli, Elements of museum mobile augmented reality for engaging hearing-impaired visitors. In AIP Conference Proceedings, 1891(1), 020033-1- 020033-6, Publishing LLC, 2017. https://doi.org/10.1063/1.5005366

[5] E. Z. Barsom, M. Graafland and M. P. Schijven, Systematic review on the effectiveness of augmented reality applications in medical training. Surgical endoscopy, 30(10), 4174-4183, 2016. https://doi.org/10.1007/s00464-016-4800-6

[6] L. C. Beaudin, Computer self-efficacy and classroom practice: what is the correlation? (Doctoral dissertation, Lethbridge, Alta.: University of Lethbridge, Faculty of Education, 1998.

[7] H. J. Becker, Pedagogical motivations for student computer use that lead to student engagement. Educational Technology, 40(5), 5-17, 2000.

[8] A. H. Behzadan and V. R. Kamat, Visualization of construction graphics in outdoor augmented reality. In Proceedings of the Winter Simulation Conference, 2005. https://doi.org/10.1109/wsc.2005.1574469

[9] M. Boberg, E. Karapanos, J. Holopainen and A. Lucero, PLEXQ: Towards a playful experience's questionnaire. In Proceedings of the 2015 Annual Symposium on Computer-Human Interaction in Play, 381-391, 2015. https://doi.org/10.1145/2793107. 2793124

[10] L. Buechley, M. Eisenberg, J. Catchen and A. Crockett, The LilyPad Arduino: using computational textiles to investigate engagement, aesthetics, and diversity in computer science education. In Proceedings of the SIGCHI conference on Human factors in computing systems, 423-432, 2008. https://doi.org/10.1145/1357054.1357123

[11] S. M. Butt and K. F. Navarro, Review paper on nutritional information using mobile augmented reality technology. In Information Science and Applications (ICISA) 2016, 14391445, Springer, Singapore, 2016. https://doi.org/10.1007/978-981-10-0557-2_137

[12] F. N. Rusli, A. N. Zulkifli, M. N. Saad and Y. M. Yussop, (A Study of Students' Motivation in Using the Mobile Arc Welding Learning App. International Journal of Interactive Mobile Technologies (iJIM), 13(10), 89-105, 2019. https://doi.org/10.3991/ ijim.v13i10.11305

[13] A. N. Weking and A. J. Santoso, A Development of Augmented Reality Mobile Application to Promote the Traditional Indonesian Food. International Journal of Interactive Mobile Technologies (iJIM), 14(9), 248-257, 2020. https://doi.org/10.3991/ijim.v14i09. $\underline{11179}$

[14] N. F. Saidin, N. D. Abd Halim and N. Yahaya, Framework for Developing a Mobile Augmented Reality for Learning Chemical Bonds. International Journal of Interactive Mobile Technologies (iJIM), 13(07), 54-68, 2019. https://doi.org/10.3991/ijim.v13i07. $\underline{10750}$

[15] A. Carlson, Aesthetics and engagement. The British Journal of Aesthetics, 33(3), 220-228, 1993.

[16] J. Carmigniani, B. Furht, M. Anisetti, P. Ceravolo, E. Damiani and M. Ivkovic, Augmented reality technologies, systems and applications. Multimedia tools and applications, 51(1), 341-377, 2011. https://doi.org/10.1007/s11042-010-0660-6

[17] Y. L. Chang, H. T. Hou, C. Y. Pan, Y. T. Sung and K. E. Chang, apply an augmented reality in a mobile guidance to increase sense of place for heritage places. Journal of Educational Technology \& Society, 18(2), 166-178, 2015.

[18] C. Y. Chen, B. R., Chang and P. S. Huang, Multimedia augmented reality information system for museum guidance. Personal and ubiquitous computing, 18(2), 315-322, 2014. https://doi.org/10.1007/s00779-013-0647-1 
[19] E. Collom, The motivations, engagement, satisfaction, outcomes, and demographics of time bank participants: survey findings from a US system. International Journal of Community Currency research, 11(1), 36-83, 2007.

[20] E. Cranmer, T. Jung, M. C. tom Dieck and A. Miller, Understanding the acceptance of augmented reality at an organisational level: the case of Geevor Tin Mine Museum. In Information and Communication Technologies in Tourism 2016, 637-650, Springer, Cham, 2016. https://doi.org/10.1007/978-3-319-28231-2_46

[21] A. Damala, I. Marchal and P. Houlier, Merging Augmented Reality based features in mobile multimedia museum guides. In Anticipating the Future of the Cultural Past, CIPA Conference 2007, 2007.

[22] A. Di Serio, M. B. Ibáñez and C. D. Kloos, Impact of an Augmented Reality system on students' motivation for a visual art course. Computers \& Education, 68, 586-596, 2013. https://doi.org/10.1016/j.compedu.2012.03.002

[23] A. Febretti and F. Garzotto, Usability, playability, and long-term engagement in computer games. In CHI'09 Extended Abstracts on Human Factors in Computing Systems, 4063-4068, 2009. https://doi.org/10.1145/1520340.1520618

[24] A. Fedosov, I. Elhart, E. Niforatos, A. North and M. Langheinrich, SkiAR: Wearable augmented reality system for sharing personalized content on ski resort maps. In Proceedings of the 7th Augmented Human International Conference 2016, 1-2, 2016. https://doi.org/10.1145/2875194.2875234

[25] V. Gopalan, A. N. Zulkifli, N. F. F. Mohamed, A. Alwi, R.Che Mat, J. A. Abu Bakar and A. Z. Saidin, Evaluation of e-star: An enhanced science textbook using augmented reality among lower secondary school student. Jurnal Teknologi, 77(29), 55-61, 2015. https://doi.org/10.11113/jt.v77.6813

[26] J. Goss, E. K. Kollmann, C. Reich and S. Iacovelli, Understanding the multilingualism and communication of museum visitors who are d/Deaf or hard of hearing. Museums \& Social Issues, 10(1), 52-65, 2015. https://doi.org/10.1179/1559689314z.00000000032

[27] B. D. Harper and K. L. Norman, Improving user satisfaction: The questionnaire for user interaction satisfaction version 5.5. In Proceedings of the 1st Annual Mid-Atlantic Human Factors Conference, 224-228, 1993.

[28] M. Hatala and R. Wakkary, Ontology-based user modeling in an augmented audio reality system for museums. User Modeling and User-Adapted Interaction, 15(3-4), 339-380, 2005. https://doi.org/10.1007/s11257-005-2304-5

[29] A. Karimi and Y. P. Lim, Children, engagement and enjoyment in digital narrative. Curriculum, technology \& transformation for an unknown future. In Proceedings of Australasian Society for Computers in Learning in Tertiary Education ascilite, Sydney, 475-483, 2010.

[30] J. Keil, L. Pujol, M. Roussou, T. Engelke, M. Schmitt, U. Bockholt and S. Eleftheratou, A digital look at physical museum exhibits: Designing personalized stories with handheld Augmented Reality in museums. In 2013 Digital Heritage International Congress (DigitalHeritage), 2, 685-688, IEEE, 2013. https://doi.org/10.1109/digitalheritage. $\underline{2013.6744836}$

[31] Y. H. Kim, D. J. Kim and K. Wachter, A study of mobile user engagement (MoEN): Engagement motivations, perceived value, satisfaction, and continued engagement intention. Decision Support Systems, 56, 361-370, 2013. https://doi.org/10.1016/j.dss.2013. $\underline{07.002}$

[32] G. Knezek, R. Christensen and D. Rice, Changes in teacher attitudes during information technology training. In Society for Information Technology \& Teacher Education International Conference, 763-766, Association for the Advancement of Computing in Education (AACE), 1997. 
[33] R. A. Krueger and M. A. Casey, Focus Groups: A Practical Guide for Applied Research, Thousand Oaks, CA: Sage, 2000.

[34] X. Luo, M. Han, T. Liu, W. Chen and F. Bai, Assistive learning for hearing impaired college students using mixed reality: a pilot study. In 2012 International Conference on Virtual Reality and Visualization, 74-81, IEEE, 2012. https://doi.org/10.1109/icvrv. $\underline{2012.20}$

[35] M.R. Lynn, Determination and quantification of content validity. Nursing Research, 35, 382-385, 1986.

[36] W. G. Mangold and D. J. Faulds, Social media: The new hybrid element of the promotion mix. Business horizons, 52(4), 357-365, 2009. https://doi.org/10.1016/j.bushor. 2009.03.002

[37] D. Marimon, C. Sarasua, P. Carrasco, R. Álvarez, J. Montesa, T. Adamek, I. Romero, M. Ortega and P. Gascó, MobiAR: tourist experiences through mobile augmented reality. Telefonica Research and Development, Barcelona, Spain, 2010.

[38] P. Milgram and F. Kishino, A taxonomy of mixed reality visual displays. IEICE TRANSACTIONS on Information and Systems, 77(12), 1321-1329, 1994.

[39] M. Mirzaei, S. Ghorshi and M. Mortazavi, Helping Deaf and hard-of-hearing people by combining augmented reality and speech technologies. In Proceedings of the 9th International Conference of Disability, Virtual Reality \& Associated Technologies, 149-158, 2012. https://doi.org/10.1109/svr.2012.10

[40] H. L. O'Brien and E. G. Toms, the development and evaluation of a survey to measure user engagement. Journal of the American Society for Information Science and Technology, 61(1), 50-69, 2010.

[41] M. K. Othman, H. Petrie and C. Power, Engaging visitors in museums with technology: scales for the measurement of visitor and multimedia guide experience. In IFIP Conference on Human-Computer Interaction, 92-99, Springer, Berlin, Heidelberg, 2011. https://doi.org/10.1007/978-3-642-23768-3_8

[42] B. S. Parton, leveraging augmented reality apps to create enhanced learning environments for deaf students. International Journal of Instructional Technology and Distance Learning, 12, 21-28, 2015.

[43] B. S. Parton, Glass vision 3D: digital discovery for the deaf. TechTrends, 61(2), 141-146, 2017. https://doi.org/10.1007/s11528-016-0090-z

[44] B. S. Parton, R. Hancock and J. Dawson, Augmented reality for deaf students: Can mobile devices make it possible? In IFIP Human-Computer Interaction Symposium, 309-312, Springer, Berlin, Heidelberg, 2010. https://doi.org/10.1007/978-3-642-15231-3_37

[45] U. C. Pendit, S. B. Zaibon and J. A. A. Bakar, Mobile AR for Cultural Heritage Site towards Enjoyable Informal Learning: A Revised Conceptual Model. Information Management and Business Review, 6(5), 239-248, 2014. https://doi.org/10.22610/imbr. $\underline{\mathrm{v} 6 \mathrm{i} 5.1121}$

[46] U. C. Pendit, S. B. Zaibon and J. A. A. Bakar, Conceptual model of mobile augmented reality for cultural heritage site towards enjoyable informal learning aspect. Jurnal Teknologi, 77(29), 123-129, 2015. https://doi.org/10.11113/jt.v77.6847

[47] D. Permadi and A. Rafi, Developing a conceptual model of user engagement for mobilebased augmented reality games. Jurnal Teknologi, 77(29), 2015. https://doi.org/10. $11113 /$ jt.v77.6804

[48] L. Phipps, V. Alvarez, S. de Freitas, K. Wong, M. Baker and J. Pettit, Conserv-AR: A virtual and augmented reality mobile game to enhance students' awareness of wildlife conservation in Western Australia. Mobile Learning Futures-Sustaining Quality Research and Practice in Mobile Learning, 214-217, 2016. 
[49] A. K. Przybylski, C. S. Rigby and R. M. Ryan, A motivational model of video game engagement. Review of general psychology, 14(2), 154-166, 2010. https://doi.org/10. $\underline{1037 / a 0019440}$

[50] J. Rassweiler, M. C. Rassweiler, M. Müller, E. Lima, B. Petrut, J. Huber, and A. Häcker, Augmented reality for percutaneous renal interventions. In Advances in Image-Guided Urologic Surgery, 203-220, Springer, New York, NY, 2015. https://doi.org/10.1007/ 978-1-4939-1450-0_17

[51] H. Regenbrecht, C. Ott, M. Wagner, T. Lum, P. Kohler, W. Wilke and E. Mueller, An augmented virtuality approach to 3D videoconferencing. In the Second IEEE and ACM International Symposium on Mixed and Augmented Reality, 2003. Proceedings, 290-291, IEEE, 2003. https://doi.org/10.1109/ismar.2003.1240725

[52] J. Sauro, Customer analytics for dummies. Newark, NJ: John Wiley \& Sons, 2015.

[53] D. T. Schaller, S. Allison-Bunnell, A. Chow, P. Marty and M. Heo, to flash or not to flash? Usability and user engagement of HTML vs. Flash. In Museums \& the Web, 2004.

[54] A. Schmidt, Implicit human computer interaction through context. Personal technologies, 4(2-3), 191-199, 2000. https://doi.org/10.1007/bf01324126

[55] G. Schraw, R. Bruning and C. Svoboda, Sources of situational interest. Journal of reading behavior, 27(1), 1-17, 1995. https://doi.org/10.1080/10862969509547866

[56] J. B. Scott, The practice of usability: Teaching user engagement through service-learning. Technical Communication Quarterly, 17(4), 381-412, 2008. https://doi.org/10.1080/ $\underline{10572250802324929}$

[57] B. K. Seo, K. Kim and J. I. Park, Augmented reality-based on-site tour guide: A study in Gyeongbokgung. In International Workshops on Computer Vision, ACCV 2010, 276-285, 2011. https://doi.org/10.1007/978-3-642-22819-3_28

[58] L. A. Shluzas, G. Aldaz and L. Leifer, Design Thinking Health: Telepresence for remote teams with mobile augmented reality. In Design Thinking Research, 53-66, Springer, Cham, 2016. https://doi.org/10.1007/978-3-319-19641-1_5

[59] D. L. Streiner, G. R. Norman and J. Cairney, Health measurement scales: a practical guide to their development and use. Oxford University Press, USA, 2015.

[60] A. Sutcliffe, Designing for user engagement: Aesthetic and attractive user interfaces. Synthesis lectures on human-centered informatics, 2(1), 1-55, 2009. https://doi.org/10. 2200/s00210ed1v01y200910hci005

[61] S. Ternier, R. Klemke, M. Kalz, P. Van Ulzen and M. Specht, ARLearn: Augmented Reality meets Augmented Virtuality. Journal of Universal Computer Science, 18, 2143-2164, 2012.

[62] C. Turbyne, P. de Koning and D. Denys, mHealth in mental healthcare: the application of mobile head-mounted displays. Journal of Technology in Behavioral Science, 2(3-4), 107108, 2017. https://doi.org/10.1007/s41347-017-0020-8

[63] E. Wachelka, Techcooltour: Discover Ancient Empires with Augmented Reality. Available: http://www.techcooltour.com/en/, 2013.

[64] L. Xie, A. N. Antle and N. Motamedi, Are tangibles more fun? Comparing children's enjoyment and engagement using physical, graphical and tangible user interfaces. In Proceedings of the 2nd international conference on Tangible and embedded interaction, 191-198, 2008. https://doi.org/10.1145/1347390.1347433

[65] F. Yaghmaie, Content validity and its estimation. Journal of Medical Education, 3 (1), 25 27, 2003.

[66] Z. Yovcheva, D. Buhalis and C. Gatzidis, Engineering augmented tourism experiences. In Information and communication technologies in tourism 2013, 24-35, Springer, Berlin, Heidelberg, 2013. https://doi.org/10.1007/978-3-642-36309-2_3 
[67] S. B. Zaibon, U. C. Pendit and J. A. A. Bakar, User requirements on mobile AR for cultural heritage site towards enjoyable informal learning. In 2015 Asia Pacific Conference on Multimedia and Broadcasting, 1-7, IEEE, 2015. https://doi.org/10.1109/apmediacast.2015. $\underline{7210289}$

\section{Authors}

Esraa Jaffar Baker is a lecturer in Computer Science at the Mustansiriyah University, Iraq. Her primary research interest focuses on multimedia systems, augmented reality, virtual reality and multimedia steganography. Her recent publications are in AIP Publishing, International Journal of Innovative Technology and Exploring Engineering and Journal of Telecommunication, Electronic and Computer Engineering (JTEC). School of Creative Industry Management and Performing Arts, Universiti Utara Malaysia, Malaysia. Email: esraajaffar26@outlook.com

Juliana Aida Abu Bakar currently is an associate professor at the School of Creative Industry Management \& Performing Arts, Universiti Utara Malaysia. She has won gold medals for innovative products in numerous exhibitions at national and international level and successfully led two projects funded by national grants for the past five years. She has published over 100 articles in the renowned journals and proceeding with an h-index 6. Her research interests include virtual reality design, development and evaluation augmented reality; and virtual heritage. Email: liana@uum.edu.my

Abdul Nasir Zulkifli is an Associate Professor at the School of Creative Industry Management \& Performing Arts, Universiti Utara Malaysia. He has been teaching in various fields including Mechanical Engineering, Manufacturing Engineering, CAD, CAM, Management of Technology, Multimedia, Virtual Reality and 3D Animation for the last 34 years. His research areas include Virtual Reality, Augmented Reality, and Mobile applications in training and education. Email: nasirzul@uum.edu.my

Article submitted 2020-06-26. Resubmitted 2020-07-26. Final acceptance 2020-07-29. Final version published as submitted by the authors. 